\title{
Planning and optimization of a multipurpose farm using renewable energies (solar) in Yaoundé (Cameroon).
}

Bertold Damesse ${ }^{1}$, Francois Damesse ${ }^{2}$, Roland Kirchberger ${ }^{1}$, Kevin Wamba ${ }^{3}$ and Markus Sperka

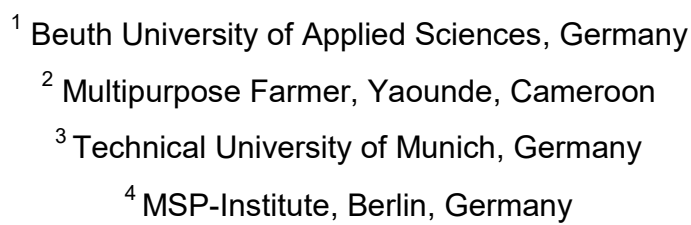

Abstract. The instability of Cameroon's electricity network leads to recurrent power outages, which constitute a significant obstacle to socio-economic activity in the region [3]. This is also the case for the agricultural activities carried out by the GIC PROSER in the MEYO area of Yaoundé. The main objective of this work is to demonstrate a solution approach for an ecologically sustainable and relatively self-sufficient solar energy supply by GIC-PROSER, thus creating a prototypical model for other farms. For this purpose, a detailed calculation of the annual energy demand was performed. A first investigation was done in order to find out the potential of wind energy, but the wind speeds are not sufficient to provide enough electrical energy due to the location of the farm. Subsequently, a thorough and optimized planning of a solar generator was made, taking into account the solar radiation data of the area. Finally, an approximate of the economic efficiency calculation of this ecological generator was shown. This results in an annual demand of 25,647 kWh/a with a peak load of $12.8 \mathrm{~kW}$. On the roofs of two farm buildings, 49 solar modules with $600 \mathrm{~W}$ each are to be installed, resulting in an output of about $29.4 \mathrm{~kW}$. The solar generator (AC grid) provides an annual energy of almost $38,794 \mathrm{kWh}$. About $32 \%$ of this energy is consumed directly by the electrical equipment on the farm. About $55 \%$ can be used for battery charging. The annual surplus of produced energy, about $4,131.90 \mathrm{kWh}$, is fed directly into the grid. This leads to a degree of autonomy of $90 \%$. This solar system costs about $16,000,000$ FCFA (24,425 EUR) and it is amortized 11 years after its installation.

Keywords: Cameroon, multipurpose farm, planning, renewable energies.

\section{Introduction}

Today, the multipurpose space MEYO has several units such as: a nursery with 5,000 trees, two poultry production units with 2,000 chickens per 45-day wave, a banana plantation, one hectare of fruit trees, a feed production unit, a pigsty and a three-story residential building. All of these units are now operational. But the normal operation of the multipurpose farm depends on a sufficient and permanent supply of electrical energy. This is not the case in the multipurpose farm as well as in several small farms in the region. The direct consequences that can be identified are: 
- Rapid aging of the multipurpose farm's electrical equipment.

- High electricity costs.

- Slowing down the economic dynamics of the multipurpose farm [4].

In addition, one of the current major difficulties is the planned relocation of the company from the current production site to a new and larger site, which is not yet covered by the electric utility. In order to overcome the various electrical problems of the multi-purpose enterprise of the GIC PROSER, different renewable energy systems have been implemented in this work. The drawing below shows an overview representation of the agro-complex of Meyo Farm. Here it is worth mentioning that the renewable energy sources drawn in Figure 1 are not yet present.

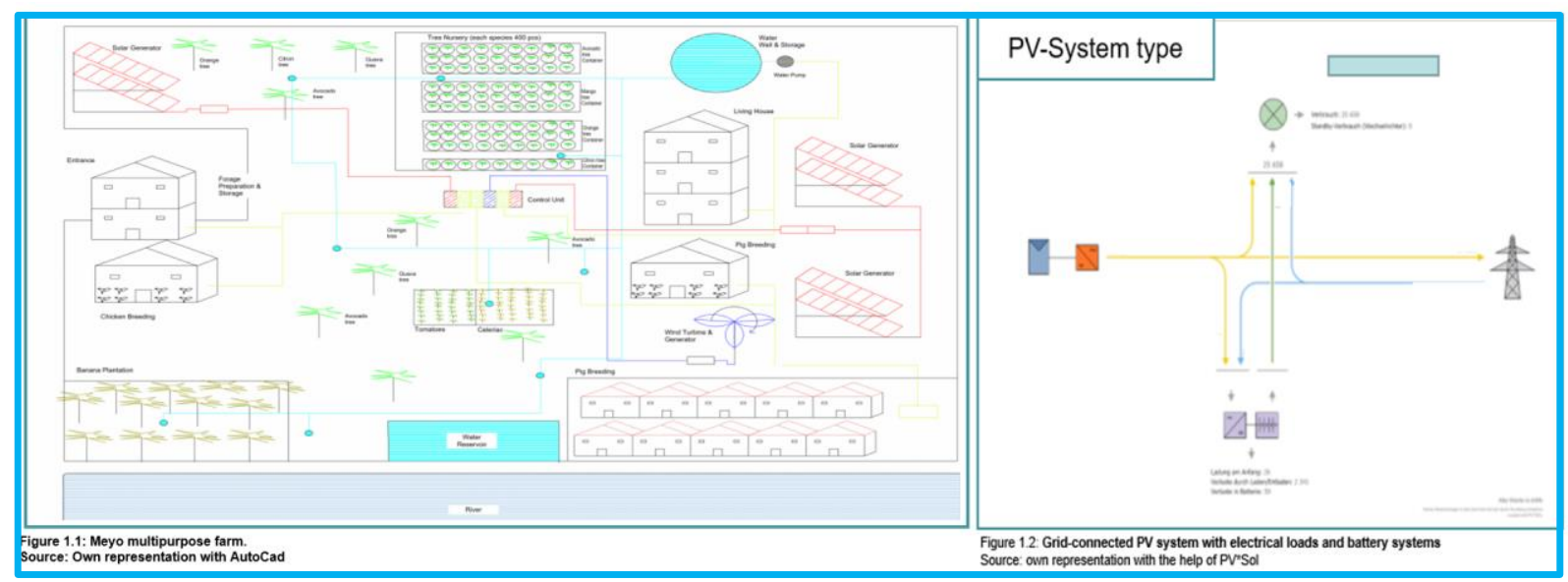

Figure 1. Meyo multipurpose farm and system type of solar generator.

\section{Requirements}

\section{Calculation of the energy demand of the multi-purpose farm.}

In the initial planning phase, all the equipment that consumes electrical energy was listed and classified according to the production unit of the multipurpose farm and the power of this equipment. The maximum average daily energy consumption of the multipurpose farm was approximately $70 \mathrm{kWh}$, considering the operating time of these devices. Then, the load management including the simultaneity factor was performed with the $\mathrm{PV}{ }^{*}$ Sol program, which reduced the peak power by about $8 \mathrm{~kW}$. The $\mathrm{PV}^{*} \mathrm{~S}$ ol simulation program was used to determine the annual energy demand of about 25,650 kWh and the peak power of $12.8 \mathrm{kWp}$ for the multipurpose operation. In Figure 2.2 below, in addition to the annual energy demand, the distribution of the consumptions according to the production unit of the multipurpose farm over the months can be seen. It can be seen that in January, for example, about 1,300 kWh are consumed by the feed production compared to the energy demand of the pig production, which is about $150 \mathrm{kWh}$ in this month.

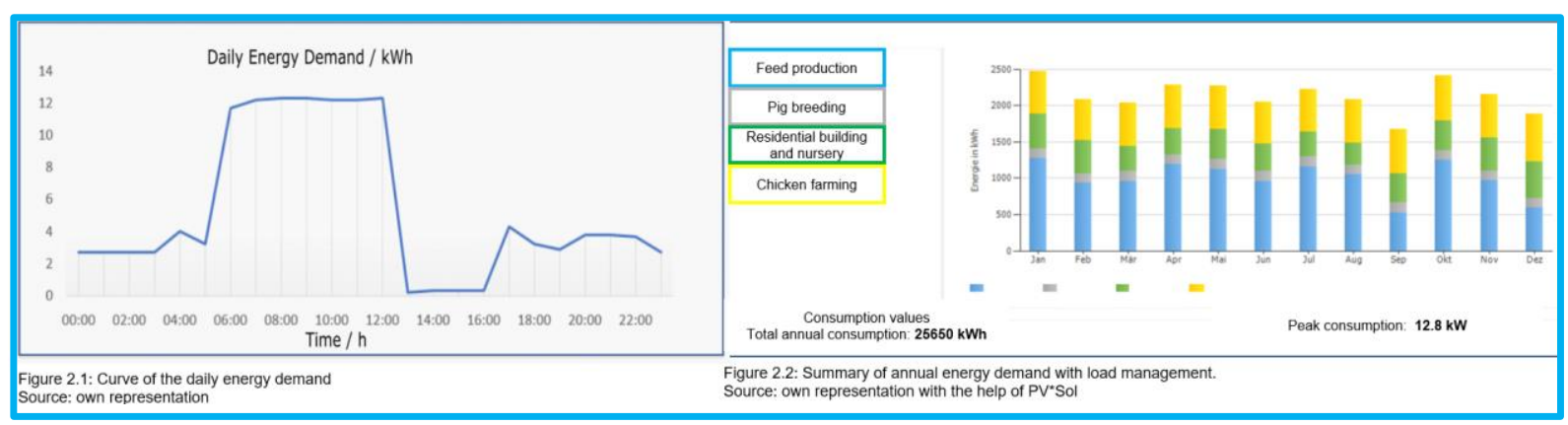

Figure 2. Summary of daily and annual energy demand with load management. 


\section{Planning of the energy supply of the multipurpose farm with the help of solar energy (simulation with PVSOL).}

\section{Solar radiation spectrum and global radiation in Yaoundé.}

The average global radiation in Cameroon is just over 3,000 hours of sunshine per year. In the more humid southern area (Yaoundé) of Cameroon, the average incident global radiation is about $1,600 \mathrm{kWh} / \mathrm{m}^{2}$. For the planning of the solar power plant, data on solar radiation in Cameroon were imported into the simulation software $\mathrm{PV}{ }^{*}$ Sol.

The system type used in this was a grid-connected PV system with electrical loads with battery storage. The battery systems increase the degree of self-sufficiency of the whole system and in case of power failures an emergency power supply will continue to run for a certain time. The selected system is shown in Fig. 1.2.

\section{Selection of the material, design of the modules and module interconnection.}

On the roof of one of the company buildings, 28 solar panels with a nominal line $600 \mathrm{~W}$ rated power from Sun Day were installed, giving a solar generator power of about $16.8 \mathrm{~kW}$. This power is much higher than the peak power required by the operation, which is $12.8 \mathrm{KW}$. An $18.7 \mathrm{~kW}$ - 3-phase inverter was used to interconnect the module (due to the existing threephase machines for feed production). To support or increase the degree of self-sufficiency of the system was used three $48 \mathrm{~V} / 200$ Ah battery systems from the company Shenzhen UFO.

\section{Dimensioning of the cables and circuit of the system}

The program $\mathrm{PV}^{*}$ Sol made it possible to enter the following information in the circuit during the simulation: (the length of the cable, the cable material, a variety of safety devices SS, LS, FI-S, TS, ÜSS, as well as the meters (one or two-sided). Then the cable cross-section (DC or $\mathrm{AC}$ side) and the cable losses are calculated automatically.

\section{Economic efficiency calculation}

For an efficient calculation of the profitability of a PV system, cost balance, investment costs, financing, taxes, operating and transport costs have been taken into account. The feed-in concept was not integrated in the economic efficiency calculation, since there is still no law in Cameroon for compensation for electricity fed into the public grid [1],

\section{Result}

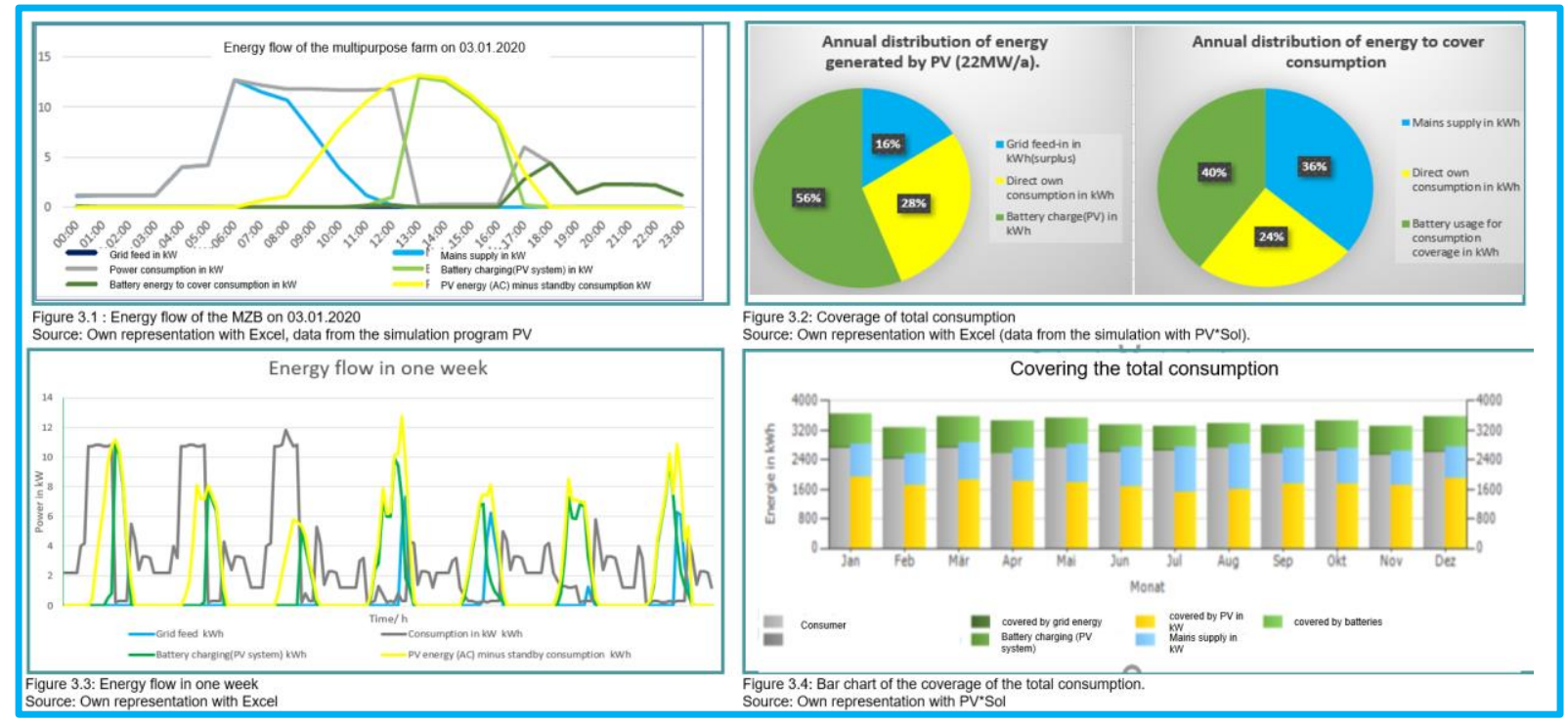

Figure 3. Compilation of results.

This system generates $22,123 \mathrm{kWh}$ per year, which is $86.6 \%$ of the farm's energy needs. $28.23 \%$ of this energy is used directly to meet demand. $55.9 \%$ is used to charge the batteries. Approximately $9,300 \mathrm{kWh}$ of energy from the grid is used to power the photovoltaic 
system. The system costs about 10,000,000 FCFA (15,260 EUR) and will be paid back 8.5 years after its implementation.

\section{Planning of the energy supply of the multipurpose farm with the help of wind power.}

A small wind turbine with a power of $10 \mathrm{~kW}$ was chosen as the second energy source. To determine the height at which the wind turbine should be planned, the first step was to determine the wind data at $10 \mathrm{~m}$ and $50 \mathrm{~m}$ above ground using wind atlas online tools. The results of the simulation allowed to make a calculation of the annual mean wind speed at $30 \mathrm{~m}$ height using the logarithmic boundary profile and the roughness factor. Then it was possible to determine the wind distributions (frequency Weibull and Rayleigh distributions) at this height. These wind turbines installed at $30 \mathrm{~m}$ height produce $24,496 \mathrm{kWh}$ of energy in this region. Due to the poor wind data in the Meyo area, the planning of the wind turbine in island mode was no longer carried out, as it is very difficult to show a payback.

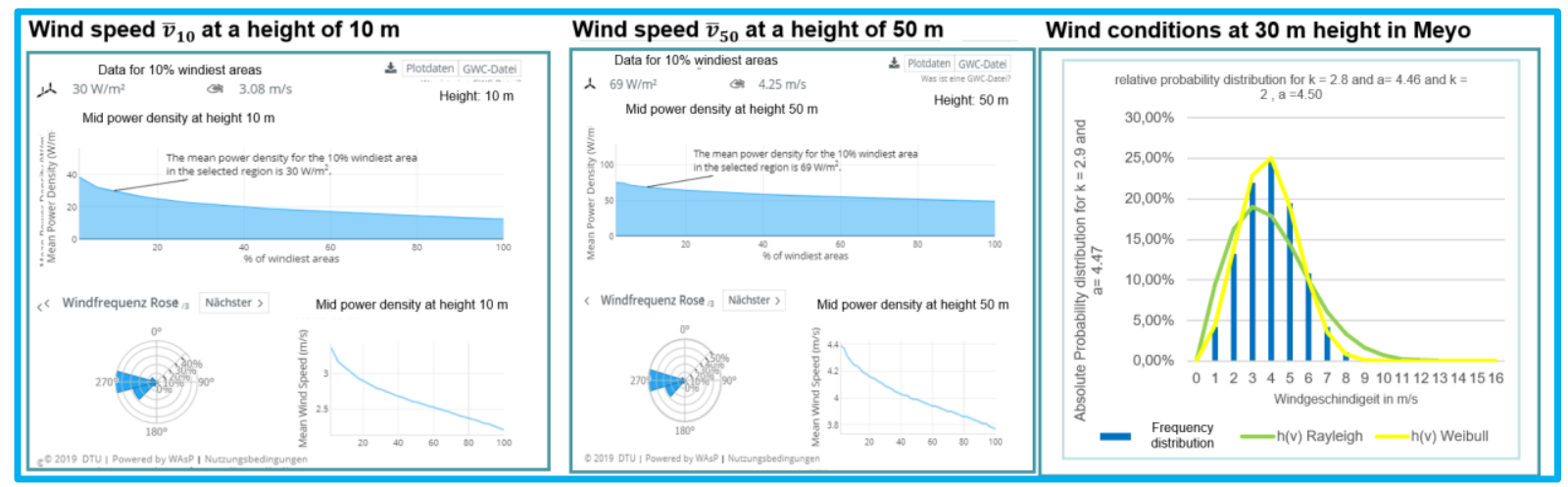

Figure 4. Wind conditions of the operating site

\section{Optimization of the solar system}

For the optimization, two three-phase inverters with $18.7 \mathrm{~kW}$ were used, a new south roof is equipped with $21 \mathrm{PV}$ modules with a total power of $12.6 \mathrm{kWp}$. The total solar system has an output of $29.4 \mathrm{kWp}$ with 21 modules each on the south roof and 28 modules on the north roof. For load optimization, the highest energy demand has a peak power of $12.8 \mathrm{kWp}$, which was between 07:00 and 13:00, was shifted by 3 hours, which seems feasible in terms of work organization. This can be seen from the red arrows in Figure 5.1 und 5.2.

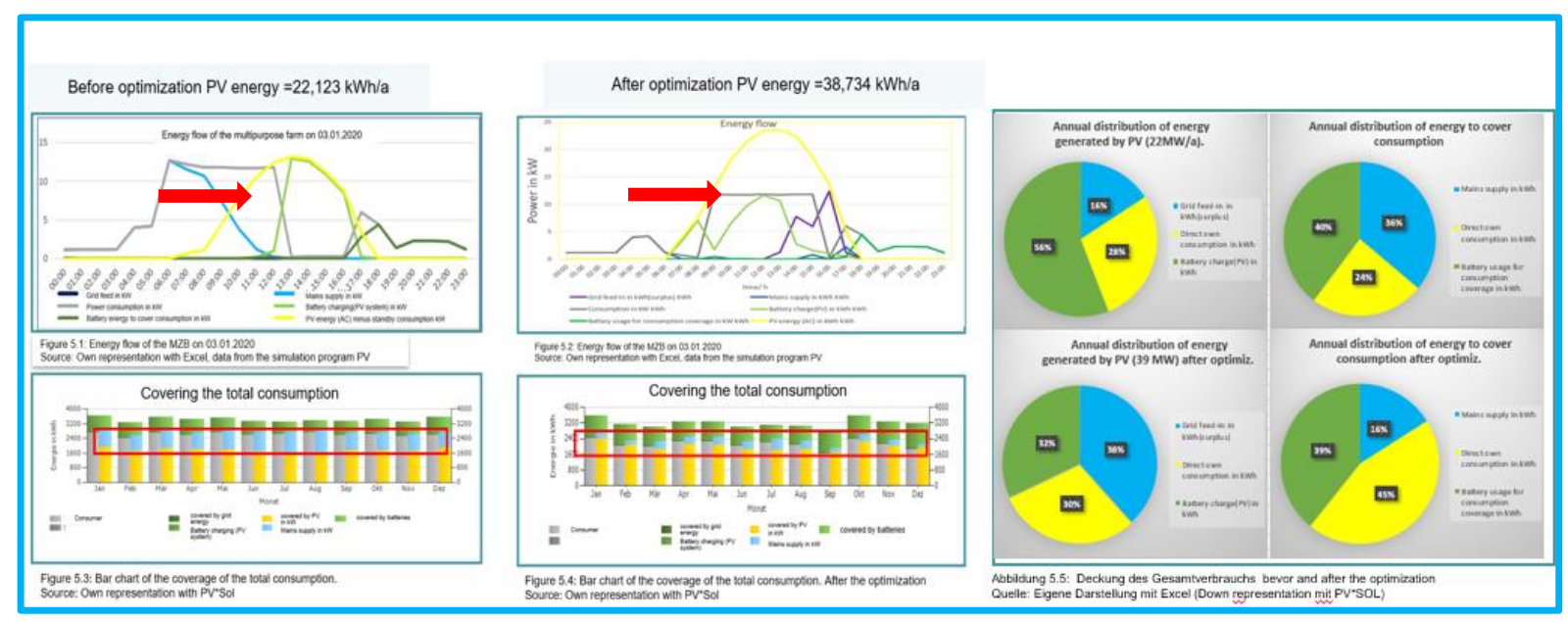

Figure 5. Compilation of results after the optimization 


\section{Simulation result after optimization}

The simulation results show that the direct energy consumption of the technical equipment in multifunctional operation almost doubled. It increased from $6,246 \mathrm{kWh} / \mathrm{a}$ to $11,515 \mathrm{kWh} / \mathrm{a}$. The system generates $38,734 \mathrm{kWh} .29 .7 \%$ of this energy, i.e., $45 \%$ of the energy demand of the multifunctional operation, this energy is used directly to meet the demand. $32 \%$ of the generated energy is used to charge the batteries. The energy purchase from the grid decreased from 9,301.60 kWh to 4,131.90 kWh (from $36 \%$ to 16\%). This leads to an increase in the degree of autonomy from $66.6 \%$ to $90 \%$. This solar system costs about 16.000.000 FCFA (24.425 EUR) and will be paid back after about 11 years after its commissioning.

\section{Conclusion}

The solar planning approach optimized in this work would have positive impacts on the multipurpose farm. These impacts are as follows: annual savings of about 1,700,000 FCFA (2,594 EUR), increased productivity which will help in the fight against malnutrition in the region, in increased economic efficiency, in diversification of production units, in rapid growth of the business, in increasing the number of trainees and in improving competitiveness.

\section{References}

[1] D. M. I. Adolphe, „Problèmes d'électrification urbaine au Cameroun: diagnostic et proposition de solutions curatives," 0203 2017. [Online]. Available:

https://www.researchgate.net/publication/314154283_Problemes_d'electrification_urb aine_au_Cameroun_diagnostic_et_proposition_de_solutions_curatives. [Zugriff am 0611 2020].

[2] H. Best, „Die Umstellung auf ökologische Landwirtschaft,“ Springerlink , Nr. 60, pp. 315-339, 20082008.

[3] Deutsche Energie-Angentur GmbH (dena), „Länderprofil Kamerun,“ Bundesministerium für Wirtschaft und Energie, Berlin , 2014.

[4] B. N. Tansi, „MASTER THESIS: AN ASSESSMENT OF CAMEROON'S RENEWABLE ENERGY RESOURCE POTENTIAL AND PROSPECTS FOR A SUSTAINABLE ECONOMIC DEVELOPMENT,“ Cottbus, 2011.

[5] Eneo Cameroon S.A, „Rapport annuel 2018,“ Douala, 2018.

[6] F. Konrad, Planung von Photovoltaik-Anlagen, Wisbaaden: Vieweg+Teubner, 2008.

[7] European Communities, „EU SCIENCE HUB,“" PVGIS, 1302 2020. [Online]. Available: https://re.jrc.ec.europa.eu/pvg_tools/en/tools.html\#PVP. [Zugriff am 2807 20].

[8] European Communities, „PVGIS users manual,“ PVGIS, 1302 20. [Online]. Available: https://ec.europa.eu/jrc/en/PVGIS/docs/usermanual. [Zugriff am 1307 20].

[9] ub.de Fachwissen $\mathrm{GmbH}$, „Photovoltaik.org,“ [Online]. Available: https://www.photovoltaik.org/photovoltaikanlagen/solarmodule. [Zugriff am 3107 2020].

[10] P. Guibert, „Master energétique et environement: TP Energie Solaire,“ Paris, 2012. 